\title{
A two year retrospective study of ovarian tumours in a rural tertiary care hospital
}

\author{
S Kalyani ${ }^{1}$, S. R. Muraliprasath ${ }^{2, *}$ \\ ${ }^{\mathbf{1}}$ Associate Professor, ${ }^{\mathbf{A}}$ Assistant Professor, Dept. of Pathology, Government Thiruvarur Medical College, Thiruvarur, Tamil \\ Nadu, India
}

*Corresponding Author: S. R. Muraliprasath

Email: mrlprasath1@gmail.com

Received: $27^{\text {th }}$ April, 2018

Accepted: $16^{\text {th }}$ May, 2018

\begin{abstract}
Introduction: The classification of ovarian tumours, both benign and malignant, into numerous categories is a proof for the ever expanding number of new lesions being added every year. This heterogeneity of ovarian lesions is the initiating factor to conduct this retrospective study to evaluate the frequency and age distribution of ovarian lesions in our tertiary centre.

Materials and Methods: This is a retrospective study conducted in the Department of pathology, Government Thiruvarur medical college, Thiruvarur, Tamil Nadu between the period Jan '2016 to Dec'2017.The clinical details along with the gross and histopathological diagnosis cases with ovarian lesions were compiled and analysed to arrive at the percentage of distribution of various lesions.

Results: Out of 144 cases studied, benign, borderline and malignant ovarian tumours were $79.85 \%, 3.47 \%$ and $16.65 \%$ respectively. Benign tumours peaked between third and fourth decades, while malignant tumours were seen commonly after fifth decade. Surface epithelial tumours were common (84\%) followed by germ cell tumours (7.64\%) and sex cord stromal tumours $(4.16 \%)$. Serous cystadenoma was more common than mucinous cystadenoma followed by mature cystic teratoma. Serous cystadenocarcinoma was the most common malignancy in our study.
\end{abstract}

Keywords: Surface epithelial tumour, Germ cell tumours, Sex cord stromal tumours.

\section{Introduction}

Globally, ovarian cancer is the sixth most common cancer in women and the seventh most common cause of cancer death. ${ }^{1}$ About 204,000 new cases and 125,000 deaths are reported annually. The rate of ovarian cancer increases with age. Early menarche and late menopause are significant risk factors. Surprisingly, high socioeconomic status is associated with an increased ovarian cancer risk and lower fertility ${ }^{1}$ There are four major types of ovarian tissue, all of which can give rise to a variety of neoplasms, often combined: ${ }^{2}$

1. Surface, coelomic, or germinal epithelium

2. Germ cells

3. Sex cords

4. Ovarian stroma, specialized and nonspecific.

The classification of surface epithelial ovarian tumors is based on the following parameters:

1. Cell type: serous, mucinous, endometrioid, etc.

2. Pattern of growth: cystic, solid, surface

3. Amount of fibrous stroma

4. Atypia and invasiveness: benign, borderline, and malignant. $^{2}$

The guidelines from the Society of gynecologic oncologists helps to identify the women with inherited predisposition to ovarian cancer. Genetic counseling and testing must be offered to women affected with high grade epithelial ovarian cancer and those women with close relatives having ovarian cancer for BRCA 1 \& BRCA $2 .^{3}$

Epithelial tumors constitutes about $60 \%$ of all ovarian neoplasms and more than $90 \%$ of malignant tumors. $^{4}$ Most are classified according to their predominant pattern of differentiation as serous, mucinous, endometrioid, mixed mesodermal, clear cell, Brenner or transitional cell, or undifferentiated. When mixtures of cell types are seen as commonly occurs minor foci of cell types other than the predominant one may be ignored, but when significant amounts $(>10 \%)$ of several cell types are present, the tumor is then termed as mixed epithelial tumor. The category "unclassified" is entitled to those tumours that do not fall into specific category. Tumors that are removed after neo adjuvant chemotherapy frequently fall into the unclassified category. ${ }^{4}$

By the time of diagnosis, most ovarian malignancies spread beyond the ovary. They account for a most number of deaths from malignancy of the female genital tract. The most common symptoms are due to abdominal pain and distension or tumor compression on urinary and gastrointestinal tract. Other symptoms are bleeding per vaginum and invasion of neighbouring structures. ${ }^{5}$

The WHO classification system of ovarian malignancies expands every year becoming more diverse as newer entities are added each year. The normal ovary has 3 major cell types -the surface coelomic epithelium, the sex cord and stromal cells. All the tumours of ovary originate from these 3 multipotential cells. Based on the morphologic presentation they are further classified into cystic, solid or adenofibromas. They are further subdivided into benign, borderline and malignant tumours based on the biologic behavior. ${ }^{6}$ Ovarian cancers represent about $30 \%$ of all cancers of the female genital tract. ${ }^{7}$ The 
Indian scenario shows an increase in the incidence rate of ovarian cancers. Identification of various histologic patterns is important in the diagnosis and prognosis. ${ }^{7}$ The invasive epithelial ovarian cancers show a peak incidence between 5th to 6th decades. In the postmenopausal women, about $30 \%$ of ovarian tumors are malignant. ${ }^{8}$ One of the most important clinical features is the age of the patient. The sex cord stromal tumors are almost always confined to single ovary and many metastatic tumours are bilateral. Most benign tumours of epithelial category are cystic. The presence of solid and papillary projections are important clues to likely malignancy. ${ }^{9}$

\section{Materials and Methods}

This retrospective study was conducted in the Department of Pathology, Government Thiruvarur Medical college, Thiruvarur in the state of Tamil Nadu. Between the period 'Jan 2016 to Dec' 2017. The specimens received were ovarian cystectomy, Total Abdominal Hysterectomy with Bilateral salpingo oophorectomy, Salpingo oophorectomy, Oophorectomy specimens from the Gynaecology Department. The formalin fixed specimens received were dissected by grossing followed by fixation, dehydration, clearing and impregnation in a automatic tissue processor. Paraffin blocks were made and sections were cut at 3 to 5 micron thickness and staining with $H \& E$ stain was done. The findings were noted and interpreted according to the WHO classification-2014 fourth edition. $^{19}$

\section{Results and Observation}

The total number of Gynecological specimens received over a period of two years in our institute was 1208 out of which number of ovarian tumours were 144. Thus, the overall incidence was $11.9 \%$. These tumours after classification according to the WHO scheme were further subdivided into benign, borderline and malignant tumours whose percentage was $79.85 \%$, $3.47 \%$ and $16.65 \%$ cases respectively. The maximum number of benign tumours were seen during third and fourth decade and maximum number of malignant tumours were seen during the fifth decade and sixth decade. Majority of tumours were surface epithelial tumours $(84 \%)$ followed by germ cell tumours $(7.64 \%)$ and sex cord stromal tumours (4.16\%). Among the benign tumours serous cystadenoma was the most common followed by mucinous cystadenoma and benign mature cystic teratoma. Among the malignant tumours, the most common type was serous cystadenocarcinoma followed by mucinous cystadenocarcinoma and adult granulosa cell tumour.

\section{Discussion}

Diagnosis of ovarian tumors is challenged by diverse pathologic conditions that can affect the ovaries and present with similar clinical and radiologic manifestations. The diagnosis can be refined by the knowledge of morphology and age-specific characteristics. ${ }^{9}$ From Table 3 , it is evident that benign tumours constitute more than $75 \%$ of all ovarian tumours and occurs more commonly in the 20-45 years age group. Surface epithelial tumours of ovary are most common of ovarian tumours in our study which correlates with studies by Gupta et al $(54.7 \%)$, Ranu et al(66.8\%), Badge et al(11) and Francisco et al (70.2\%). ${ }^{6}$ Among benign surface epithelial tumours, serous cystadenomas were most common, which was different from study by Mankar et al. ${ }^{6}$ But studies by other authors like Shah et al and Thanikachalam et al show that serous cystadenomas were the most common benign ovarian tumours. The highest number of malignant tumours were diagnosed in the 41-60 years age group in the Mankar et al study. ${ }^{7}$ In our study the lowest age group for malignancy was 26 years pointing out to an increasing incidence of malignancy in the age group less than 40 years. Endometriotic cysts are important lesions commonly found in reproductive women. Most common location of endometriosis is ovary. In our study one case of endometriotic cyst was reported. Gupta et al, Carey et al and Clement et al had reported 2 cases of endometriosis. ${ }^{8}$ Most of the benign and borderline tumours were unilateral and bilaterality was common in malignant tumours. ${ }^{9}$ The most common bilateral tumour was serous cystadeno carcinoma in our study. ${ }^{9}$ Similar to Pili et al. The histopathological type of ovarian tumour and prognosis of the tumours correlate with each other in terms of response to chemotherapy, patterns of spread and precursor lesions. $^{10}$ Many ovarian tumours may remain asymptomatic or cause mild abdominal pain and distension due to their anatomic location. ${ }^{11}$ Bilateral ovarian tumours were seen more in malignant tumours than benign tumours. The percentage of bilateral malignant tumours was $7 / 16(43 \%)$ where as benign tumours showed a $12 \%(11 / 85)$. This is comparable to findings of R Jha et al. ${ }^{13}$ In our study, we had 5 cases of high grade serous carcinoma, which is enlisted in the current classification of epithelial ovarian cancers by WHO 2014 edition. ${ }^{19}$ The Five major categories are high grade serous, low grade serous, endometrioid, clear cell and mucinous carcinomas. High grade serous carcinoma (HGSC) is a distinct entity and originates from the epithelium of the distal fimbrial portion of the fallopian tube. ${ }^{14}$ In our study a case of squamous cell carcinoma of the ovary arising in a mature cystic teratoma of the ovary is reported. The incidence of this rare tumour is up to $2 \% .{ }^{15}$ Preoperative diagnosis could be difficult but may be aided by MRI. Carcino Embryonic Antigen (CEA) may be elevated. Takagi et al have found CEA to be more useful than CA 125 and CA 19-9 in malignant transformation of MCT. This transformation makes the prognosis very poor especially when diagnosed in advanced stage. ${ }^{15}$ Next rare entity in our study was a case of fibrosarcoma of 
ovary. Ovarian fibrosarcoma arises directly from stromal cells around the sex cord of ovarian follicles. Although diagnosed mostly in menopausal and postmenopausal women, they can occur at any age. Majority of them show areas of necrosis and haemorrhage, disruption of capsule, and infiltration of tumour thus causing tumor adhesion with other pelvic organs. ${ }^{16}$ The assessment of malignant potential of ovarian fibrosarcomas.

Is based on the growth patterns, nuclear atypia, and mitotic counts. ${ }^{17}$ Immature teratoma constitutes about $3 \%$ of all teratomas, $1 \%$ of all ovarian cancers and $20 \%$ of malignant ovarian germ cell tumors. It is defined on the basis of presence of immature primitive neuroectodermal tissue. Immature elements reflect the evolution of a malignant clone, and the prognosis depends on the amount of this component. It is almost always unilateral. Immature teratoma is a tumor of children and adolescents and occurs during the first two decades of life. ${ }^{18}$ The only case of secondary carcinoma of ovary in our study is a case of bilateral ovarian metastatic carcinoma from uterine endometrial carcinoma. (Grade II endometrioid with micropapillary architecture) Although uncommon, the simultaneous presence of carcinoma in the ovary and uterus is wellrecognized. The two tumors may look similar (usually endometrioid but sometimes papillary serous, clear cell, or mucinous) or different by histology. The 3 theoretical possibilities are (1) metastasis from an endometrial carcinoma into the ovary; (2) two independent primary tumors; or (3) metastasis from an ovarian carcinoma to the endometrium. The first two possibilities cannot be easily distinguished. Certain findings such as multiplicity, bilaterality, and/or very small size of the ovarian tumor, involvement of the tubal lumen, and presence of deep myometrial invasion and/or vascular invasion in the uterine tumor favor ovarian metastasis from an endometrial tumor. An endometrioid histological picture in both sites favors the possibility of independent neoplasms carrying an excellent prognosis. ${ }^{21,22}$

Young et al. E31 in 1984 and Ulbright in 1985 have devised criteria for the diagnosis of ovarian metastasis of endometrial carcinoma: ${ }^{22}$ (1) The ovarian carcinoma appears in multinodular growth, the unattached carcinoma nodes in the cortex and medulla of the ovary can be seen under the microscope. (2) The ovarian carcinoma is complicated with no less than two of the following instances: ovarian carcinoma $<5 \mathrm{~cm}$ invasion and bilateral ovarian invasion and salpinx invasion. ${ }^{20}$

Table 1: Age incidence of ovarian tumours. $(n=144)$

\begin{tabular}{|l|c|c|c|}
\hline Age range & \multicolumn{3}{|c|}{ Number of cases } \\
\hline Years & Benign & Borderline & Malignant \\
\hline $11-20$ & 5 & 0 & 0 \\
\hline $21-30$ & 42 & 1 & 2 \\
\hline $31-40$ & 41 & 0 & 3 \\
\hline $41-50$ & 15 & 2 & 7 \\
\hline $51-60$ & 7 & 2 & 8 \\
\hline $61-70$ & 1 & 0 & 4 \\
\hline $71-80$ & 3 & 0 & 0 \\
\hline $81-90$ & 1 & 0 & 0 \\
\hline Total & 115 & 5 & 24 \\
\hline
\end{tabular}


Chart 1: Age distribution of benign, borderline and malignant ovarian lesions

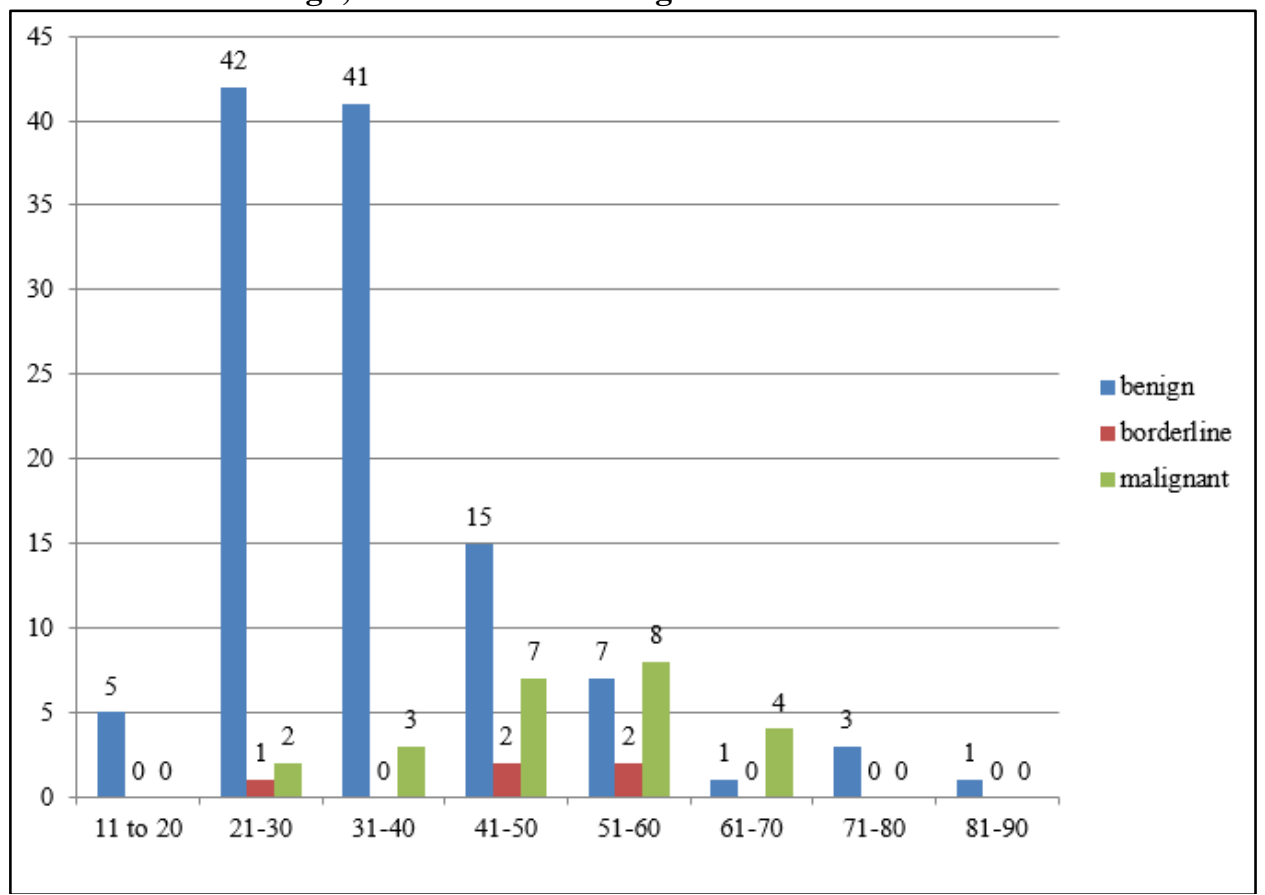

Table 2: Percentage distribution of different ovarian tumours: (total: 144)

\begin{tabular}{|l|l|l|}
\hline \multicolumn{1}{|c|}{ Tumours } & \multicolumn{1}{|c|}{ Number } & \multicolumn{1}{c|}{ Percentage (\%) } \\
\hline Surface Epithelial Tumours & 121 & 84.03 \\
\hline 1. Benign: & 58 & \\
a. Serous cystadenoma & 37 & 40.28 \\
b. Mucinous cystadenoma. & 1 & 25.69 \\
c. Benign Brenner tumour. & & 0.69 \\
\hline 2. Borderline: & 1 & \\
a. Serous borderline. & 4 & 0.69 \\
b. Mucinous borderline. & & 2.78 \\
\hline 3. Malignant: & 16 & \\
a. Serous cystadenocarcinoma. & 4 & 11.11 \\
b. Mucinous Cystadenocarcinoma. & & 2.78 \\
\hline Germ Cell Tumours: & 11 & \\
A. Benign mature cystic teratoma. & 1 & 7.64 \\
Malignant: & 1 & \\
1. Squamous cell carcinoma in teratoma. & & 0.69 \\
2. Immature Teratoma. & 2 & 0.69 \\
\hline Sex Cord Stromal Tumours: & 2 & 1.39 \\
1. Granulosa cell tumour & 1 & 1.39 \\
2. Fibrothecoma. & & 0.69 \\
3. Scelrosing stromal tumour & 1 & \\
Malignant: & & 0.69 \\
1. Fibrosarcoma & 1 & 0.69 \\
\hline Secondary or Metastatic Tumours: & & \\
1. Uterine endometrioid carcinoma metastasis \\
to ovary.
\end{tabular}


Table 3: Comparison with other studies (\%)

\begin{tabular}{|c|c|c|c|c|}
\hline Histological type & $\begin{array}{c}\text { Our study } \\
\text { (144 cases) }\end{array}$ & $\begin{array}{c}\text { Gupta et al (340 } \\
\text { cases) }\end{array}$ & $\begin{array}{c}\text { Ranu Sarkar } \\
\text { (130 cases) }\end{array}$ & $\begin{array}{l}\text { Francisco } \\
\text { Couto et al } \\
\end{array}$ \\
\hline Surface Epithelial Tumours & 84.02 & 54.7 & 66.8 & 70.27 \\
\hline $\begin{array}{l}\text { 1. Benign: } \\
\text { a. Serous cystadenoma } \\
\text { b. Mucinous cystadenoma. } \\
\text { c. Benign brenner tumour }\end{array}$ & $\begin{array}{c}40.28 \\
25.69 \\
0.69 \\
\end{array}$ & $\begin{array}{c}11.8 \\
20.59 \\
-\end{array}$ & $\begin{array}{c}19.5 \\
21.6 \\
-\end{array}$ & $\begin{array}{c}30.32 \\
24.20 \\
-\end{array}$ \\
\hline $\begin{array}{l}\text { 2. Borderline: } \\
\text { a. Serous borderline. } \\
\text { b. Mucinous borderline. }\end{array}$ & $\begin{array}{l}0.69 \\
2.78\end{array}$ & $\begin{array}{l}2.1 \\
2.1\end{array}$ & $\begin{array}{l}1.6 \\
1.6\end{array}$ & $\begin{array}{l}0.8 \\
0.8\end{array}$ \\
\hline $\begin{array}{l}\text { 3. Malignant: } \\
\text { a. Serous cystadenocarcinoma. } \\
\text { b. Mucinous Cystadenocarcinoma. }\end{array}$ & $\begin{array}{c}11.11 \\
2.78\end{array}$ & $\begin{array}{c}14.71 \\
4.12 \\
\end{array}$ & $\begin{array}{c}11.1 \\
4.7\end{array}$ & $\begin{array}{l}7.58 \\
2.05\end{array}$ \\
\hline $\begin{array}{l}\text { Germ Cell Tumours: } \\
\text { A. Benign mature cystic teratoma. } \\
\text { Malignant: } \\
\text { 1. Squamous cell carcinoma in teratoma. } \\
\text { 2. Immature Teratoma }\end{array}$ & $\begin{array}{l}7.64 \\
0.69 \\
0.69 \\
\end{array}$ & $\begin{array}{c}23.13 \\
- \\
- \\
\end{array}$ & $\begin{array}{l}16.9 \\
- \\
- \\
\end{array}$ & $\begin{array}{c}15.45 \\
- \\
- \\
- \\
\end{array}$ \\
\hline $\begin{array}{l}\text { Sex Cord Stromal Tumours: } \\
\text { 1. Granulosa cell tumour } \\
\text { 2. Fibrothecoma. } \\
\text { 3. Scelrosing stromal tumour } \\
\text { Malignant: } \\
\text { 1. Fibrosarcoma }\end{array}$ & $\begin{array}{l}1.39 \\
1.39 \\
0.69 \\
0.69\end{array}$ & $\begin{array}{c}4.43 \\
- \\
- \\
-\end{array}$ & $\begin{array}{l}1.6 \\
- \\
- \\
-\end{array}$ & $\begin{array}{c}1.17 \\
- \\
- \\
-\end{array}$ \\
\hline $\begin{array}{l}\text { Secondary or Metastatic Tumours: } \\
\text { 1. Uterine endometrioid carcinoma } \\
\text { metastatic to ovary. }\end{array}$ & 0.69 & - & - & - \\
\hline $\begin{array}{l}\text { Others: } \\
\text { 1. Ovarian leiomyoma. } \\
\text { 2. Endometriotic cysts. }\end{array}$ & $\begin{array}{l}0.69 \\
1.39\end{array}$ & $\begin{array}{l}- \\
-\end{array}$ & - & $\begin{array}{l}- \\
-\end{array}$ \\
\hline
\end{tabular}

Table 4: Laterality of ovarian tumours in the present study

\begin{tabular}{|l|c|c|c|}
\hline \multicolumn{1}{|c|}{ Diagnosis } & Bilateral & Unilateral & Total \\
\hline Benign & & & \\
\hline Serous cystadenoma & 7 & 40 & 47 \\
\hline Mucinous cystadenoma & 3 & 22 & 25 \\
\hline Benign Brenner tumour. & 0 & 1 & 1 \\
\hline Mature cystic teratoma & 1 & 7 & 8 \\
\hline Fibrothecoma. & 0 & 2 & 2 \\
\hline Sclerosing stromal tumour & 0 & 1 & 1 \\
\hline Ovarian leiomyoma & 0 & 1 & 1 \\
\hline Total & 11 & 74 & 85 \\
\hline Malignant & & & \\
\hline Serous cystadenocarcinoma & 5 & 2 & 7 \\
\hline Mucinous cystadenocarcinoma & 2 & 3 & 5 \\
\hline Immature teratoma & 0 & 1 & 1 \\
\hline Granulosa cell tumour & 0 & 2 & 2 \\
\hline Yolk sac tumour & 0 & 1 & 1 \\
\hline Metastasis & 1 & - & - \\
\hline Total & 8 & 9 & 16 \\
\hline
\end{tabular}




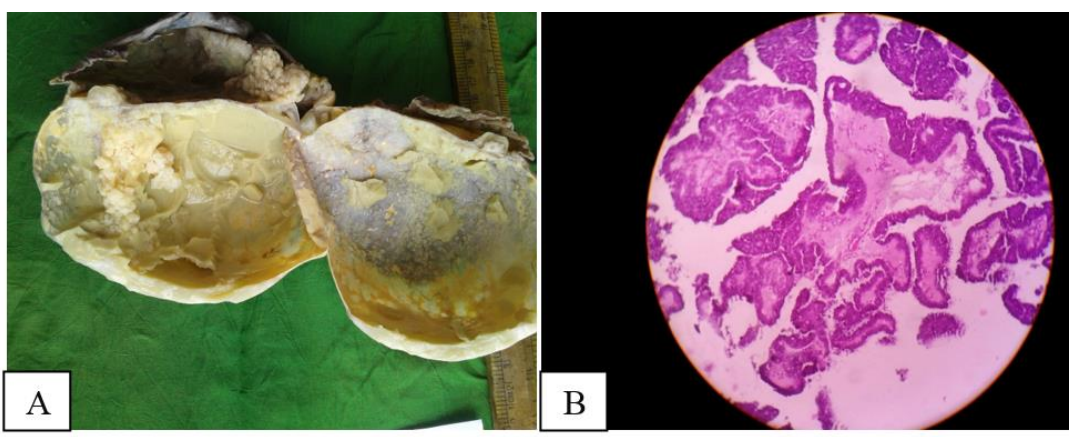

Fig. 1. Papillary serous cystadenocarcinoma. A: Gross picture showing large friable multiloculated cyst with papillary projections; B: Microphotograph showing papillary architectural pattern of growth with stromal invasion
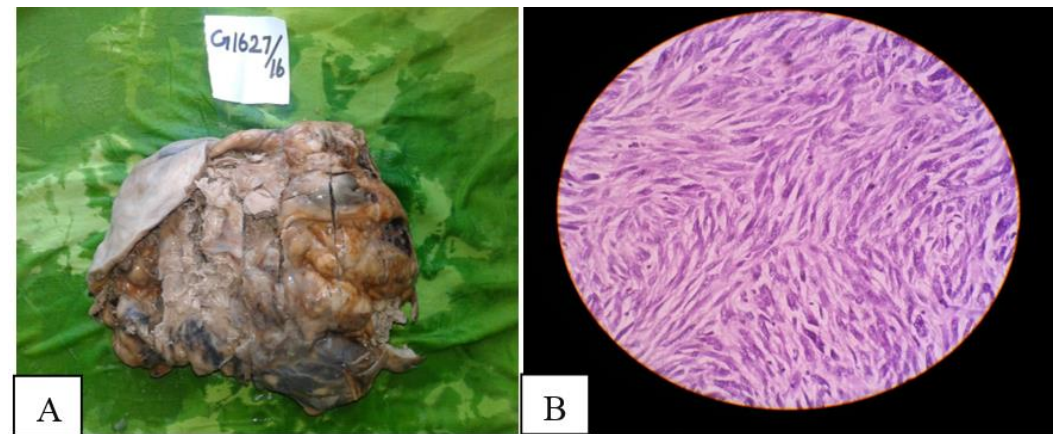

Fig. 2: Ovarian Sarcoma. A: Gross picture showing solid appearance with tan yellow discoloration and areas of necrosis; B: Microphotograph showing densely packed spindle cells with elongated hyperchromatic nuclei and with increased mitotic activity

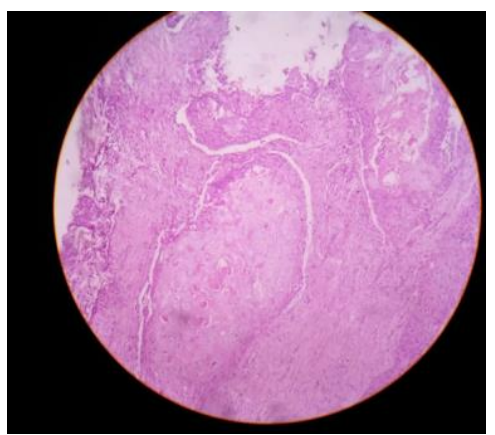

Fig. 3: Microphotograph showing squamous cell carcinoma with tongue of malignant squamous epithelial rest in a teratoma
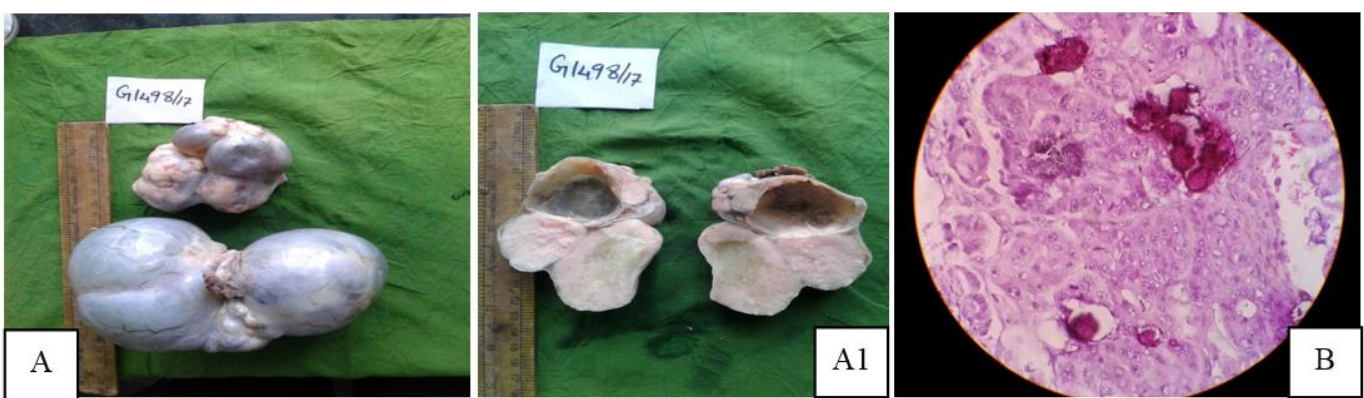

Fig. 4: High grade serous carcinoma. (A\&B).

A \&A1. Gross picture showing high grade serous carcinoma(bilateral)ovarian tumour; B: Microphotograph showing high grade serous carcinoma with psammomatous calcifications. The tumour cells display high grade nuclear features and pleomorphism. $(40 \mathrm{X})(\mathrm{H} \& \mathrm{E})$. 

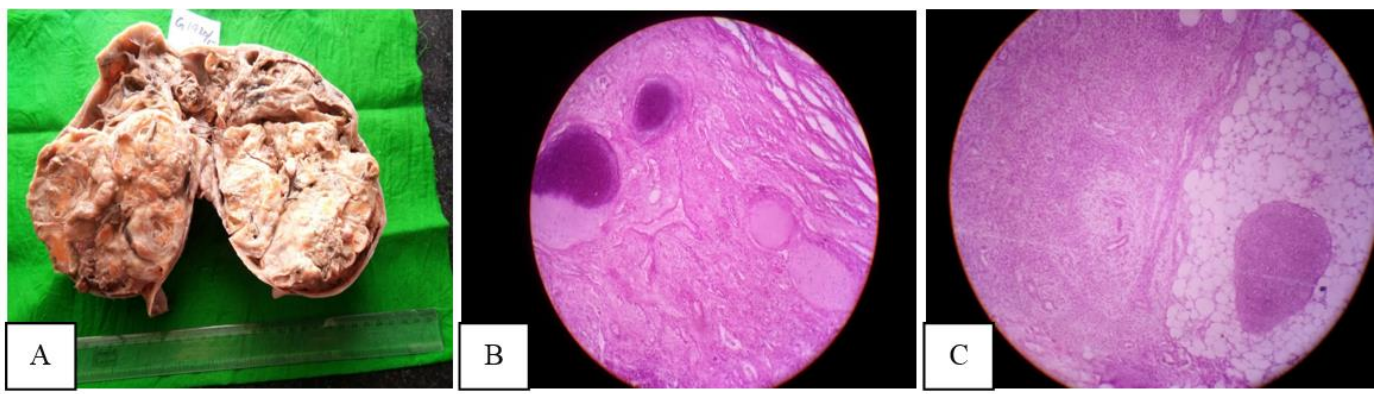

Fig. 5: Immature Teratoma. Gross (A) and microscopic; (B) \&(C): A. Showing extensive solid and few cystic components. B. showing immature cartilage elements and $\mathrm{C}$ showing immature neuroepithelium
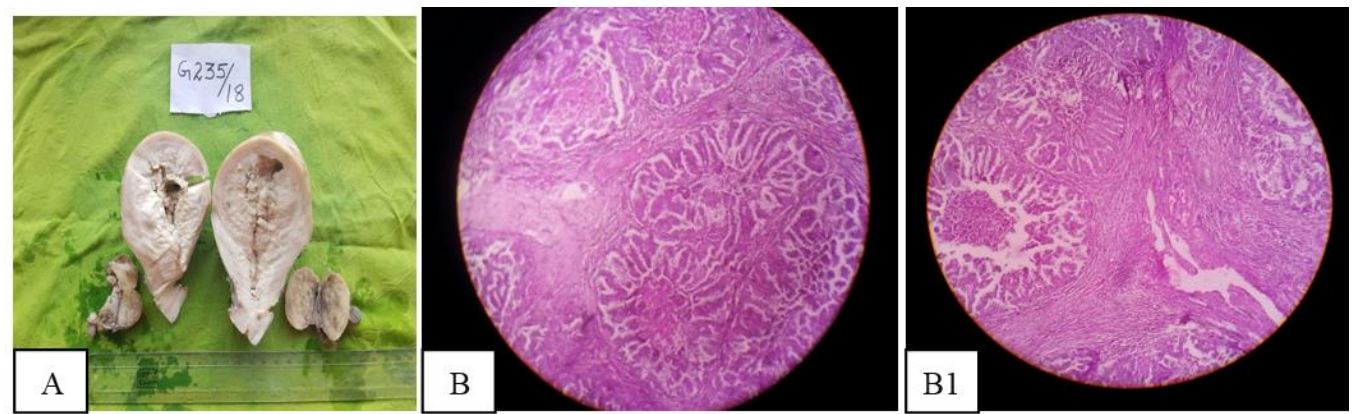

Fig. 6: Bilateral ovarian metastases from uterine endometrioid carcinoma; A. Gross and; B: \& B1 Microscopic

\section{Conclusion}

The study clearly shows surface epithelial tumours were the most common of all ovarian tumours. Benign tumours were more common than malignant tumours especially serous cystadenoma followed by mucinous cystadenoma. Serous cystadenocarcinoa was the most common malignant tumour.

\section{References}

1. Kurman RJ, Ellenson LH, Ronnett BM, Blaustein's pathology of the female genital tract, $6^{\text {th }}$ edition, NewYork: Springer:2011 p.680-682.

2. Rosai J. Rosai and Ackerman's Surgical Pathology. Tenth edition, New York: Mosby Elsevier; 2011 p.1562-1563.

3. Crum. P.C and Lee KR et al. Diagnostic Gynecologic and obstetric pathology, 2nd edition, Philadelphia:

Elsevier:2011.p.782.

4. Christopher D.M.Fletcher. editor Diagnostic Histopathology of Tumours. Fourth edition, Philadelphia, Elsevier Saunders: 2013.p.658.

5. Kumar V, Abbas AK, Asler JC Robbins and Cotran Pathologic Basis of Disease, $9^{\text {th }}$ Edition, Elsevier Saunders, Philadelphia 2015p.1023.

6. Sharma I, Sarma V, Dutta VC Pathology of Ovarian Tumours-A Hospital based study; vol:1/issue 6/p284-286.

7. Mankar DV, Jain GH. Histopathological Profile of Ovarian tumours: A twelve year institutional experience. Muller J Med Sci Res. 2015;6:107-11.

8. S.N., Kanthikar. "Clinico-Histopathological Analysis of Neoplastic and Non-Neoplastic Lesions of the Ovary: A 3-Year Prospective Study in Dhule, North Maharashtra, India. Journal of Clinical and Diagnostic Research. JCDR. 8.8 (2014): FC04-FC07. PMC. Web. 22 July 2017.

9. Mondal SK, Banyopadhyay R, Nag DR, Roychowdhury S, Mondal PK, Sinha SK. Histologic pattern, bilaterality and clinical evaluation of 957 ovarian neoplasms: A 10year study in a tertiary hospital of eastern India. $J$ Can Res Ther. 2011;7:433-7.

10. Agrawal. Clinicopathologic spectrum of ovarian tumours: A 5 year experience in a tertiary health care centre. Journal of Basic and Clinical reproductive sciences. 2015;4(2):90-96.

11. Nishal AJ, Naik KS, Modi J. Analysis of spectrum of ovarian tumours: a study of 55 cases. Int J Res Med Sci. 2015;3:2714-7.

12. Badge SA, Gosavi AV, Sulhyan KR, Histopathological study of Ovarian Tumours. Indian Medical Gazette-Sept. 2013.p345-351.

13. R Jha, Histological pattern of Ovarian Tumours and their age distribution. Nepal Med Coll J. 2008;10(2):81-85.

14. Singh N, Mc Cluggage W G \& Gilks C B High grade serous carcinoma of tubo-ovarian origin: Recent developments. Histopathology 2017;71:339-356. https://doi.org/10.1111/his.13248.

15. Patni R. Squamous cell carcinoma arising in mature cystic teratoma of ovary. Journal of Mid-Life Health. 2014;5(4):195-197. doi:10.4103/0976-7800.145169.

16. Huang. Clinicopathologic characteristics and prognostic factors of ovarian fibrosarcoma: the results of a multicenter retrospective study. BMC Cancer. 2010;10:585.

17. Prat J, Scully RE: Cellular fibromas and fibrosarcomas of the ovary: a comparative clinicopathologic analysis of seventeen cases. Cancer. 1981;47:2663-2670

18. Gheorghisan-Galateanu et al.: Immature ovarian teratoma with unusual gliomatosis. Journal of Ovarian Research. 2013;6:28

19. Robert J. Kurman, Maria Luisa Carcangiu, C. Simon Herrington, Robert H. Young, (Eds.): WHO Classifi cation of Tumours of Female Reproductive Organs $4^{\text {th }}$ edition IARC Lyon. 2014 p.12-13.

20. Feng-zhi Zhou, Yi-nan Chen, Guo-nan Zhang. Ovarian metastasis in patient with endometrial carcinoma. Chinese Journal of Cancer Research, 2005;17(3):230. 
21. Robboy SJ, Datto MB: Synchronous endometrial and ovarian tumors: metastatic disease or independent primaries?. Hum Pathol. 2005;36:597-599.

22. Ulbright TM, Roth LM: Metastatic and independent cancers of the endometrium and ovary. A clinicopathologic study of 34 cases. Hum Pathol. 1985;16:28-34.

How to cite this article: Kalyani S, Muraliprasath S.R. A two year retrospective study of ovarian tumours in a rural tertiary care hospital. Indian J Pathol Oncol. 2018;5(4):563570. 